\title{
Fibroadenoma with Foci of Infiltrating Ductal Carcinoma
}

\author{
FAUZIA JAHAN, ${ }^{1}$ PK GHOSH, ${ }^{2}$ SAIDUR RAHMAN, ${ }^{3}$ REHANA KHANAM ${ }^{4}$
}

\begin{abstract}
:
Fibroadenoma is a biphasic tumor of breast with stromal and epithelial components. It is a very common benign tumor among young female. Malignant transformation in a fibroadenoma is uncommon. We report a case of an elderly patient with bilateral fibroadenomas harboring foci of invasive ductal carcinoma. The intent of this presentation is to increase general awareness as to the existence of carcinomas arising in fibroadenomas and also to actively discourage the practice of rendering gross pathological diagnoses of fibroadenomas.
\end{abstract}

Keyword: Fibroadenoma, infiltrating ductal carcinoma.

\section{Introduction:}

Benign breast disease has a high prevalence rate with fibroadenoma occurring in one of every five women. One of every two women is affected by fibrocystic disease. ${ }^{1}$ Fibroadenoma is the most common benign tumor of the young female. Other benign lesions are adenosis and proliferative epithelial changes such as mild, moderate, florid ductal and lobular hyperplasia. Rarely, lobular and ductal non-invasive and invasive carcinoma may occur within fibroadenoma. In 1931 the first reported case was published to describe as carcinoma arising in fiboradenoma. ${ }^{2}$

Fibroadenoma, a biphasic tumor with stromal and epithelial component, is generally a benign tumors of not much concern. Malignant changes within fibroadenoma are an uncommon feature and is usually an incidental finding following the excision of fibroadenoma.

\section{Case report:}

A Female of 55 years complained of lump in both breasts for 20 years. The mass increased in size during last three months. She also complained of occasional pain. Bilateral lumpectomy was done for recent increase in size. Before surgery relevant investigations were done like ultrasonography but FNAC was not performed.

After surgery naked eye examination of the specimen revealed two nodular pieces of tissue. The larger one measured $5 \times 4 \times 3$ and smaller one $4 \times 4 \times 3 \mathrm{~cm}$. The cut surface was gray white and granular.

Histopathological examination showed anaplastic duct epithelial cells arranged in clusters and islands. In some areas evidence of invasion are present in the stroma. Foci of comedonecrosis are also seen. In peripheral areas features of fibroadenoma was also noted. Some of the ducts were slit like and lined by anaplastic epithelial cell.

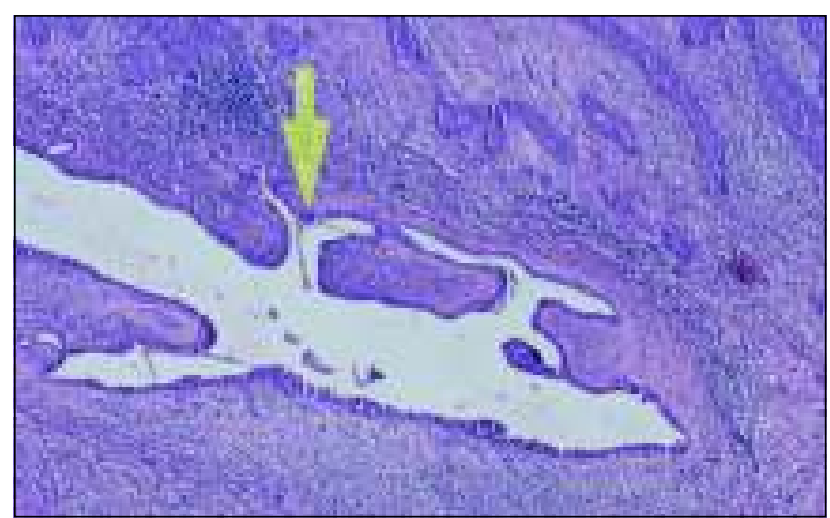

Fig.-1: Section show anaplastic duct epithelial cells arranged in clusters and islands. In some areas evidence of invasion are present in the stroma.

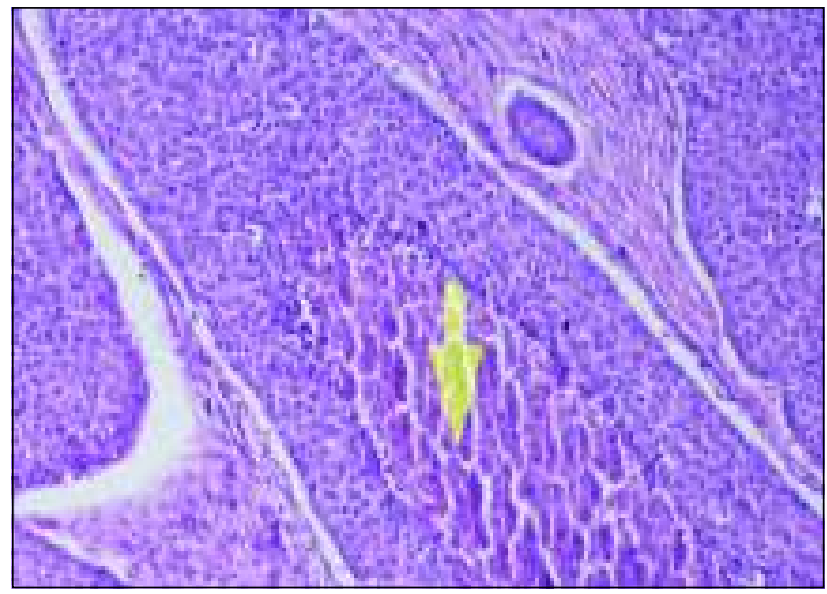

Fig.-2: Section show anaplastic duct epithelial cells arranged in clusters and islands. Foci of comedonecrosis are also seen.

1. Asst. Professor, Department of Pathology, BMC

2. Professor and Head, Department of Pathology, BMC

3. Asst. Professor, Department of Pathology, BMC

4. Associate Professor, Department of Pathology, BMC

Correspondence: Dr. Fauzia Jahan, Asst. Professor, Department of Pathology, Bangladesh Medical College 


\section{Discussion:}

The incidence of carcinoma within fibroadenoma is not common and reported to be between $0.1 \%$ and $0.3 \%$ in a screened population, with a peak age of occurrence between 42 and 44 years. ${ }^{3-14}$ The reported mean age in various case series is 42.5 years, which is about 20 years later than the peak age of occurrence of fibroadenoma. ${ }^{7}$

Epithelial hyperplasia is a common finding within fibroadenomas. Atypical hyperplasia of either ductal or lobular type are infrequent findings. ${ }^{15}$ Some authors found atypical hyperplasia in only $0.81 \%$ of fibroadenomas ${ }^{(15)}$. Review of literature reveals a few case studies with insitu or invasive ductal and lobular carcinoma in a fibroadenoma. ${ }^{4,5,16}$

Two-thirds of carcinomas within fibroadenoma are lobular and one-third is

ductal or mixed ductal and lobular. Lobular and ductal carcinoma in situ has an approximately equal frequency. ${ }^{6-14}$

Complex fibroadenomas occur in older women with feature of calcification, apocrine metaplasia, sclerosing adenosis and cyst formation. ${ }^{6}$ It is the complex fibroadenoma, which needs greater attention, as the risk of malignant transformation is higher in this subset. ${ }^{17}$ It has been found that the risk of malignancy in complex fibroadenoma is 1.89 times higher than that of conventional fibroadenoma. ${ }^{6}$

Although the malignant transformation of a fibroadenoma is rare, the presence of this tumor in a woman with a positive family history may have greater clinical importance than fibroadenomas arising in women with no additional risk factors. ${ }^{3,8,13,18,19}$ Therefore one needs to have a high suspicion index for malignancy in a case of fibroadenoma in an older woman particularly in one with associated risk factors like strong family history. Clinicians, radiologists and pathologists need to be aware of the possible yet uncommon stepwise progression capabilities of fibroadenomas.

Triple test done to evaluate breast lesions include FNAC, core biopsy and radio-imaging techniques such as ultrasound and mammogram. Fine needle aspiration cytology is an important tool that helps in guiding the surgeon to decide further management.

Despite the low percentage of carcinoma occurring within fibroadenoma we consider that each lump should be seriously managed; extirpation and histological examination is recommended. Special caution has to be taken in females older than 35 years presenting with a fibroadenoma. Prognosis depends on the grade and the stage at presentation but fibroadenoma may attract early attention leading to early detection and good outcome.

\section{Conclusion:}

To conclude, the case report highlights the need for extensive tissue sampling in fibroadenomas as the clinico-radiological features of malignant transformation may be quite subtle to be easily missed on routine examination.

\section{Conflict of Interest: None}

\section{References:}

1. Friedenreich C, Bryant H, Alexander F, Hugh J, Danyluk J, Page D. Risk factors for benign proliferative breast disease. Int J Epidemiol 2000; 29:637-44

2. Cheatle GL, Cutler M: Tumours of the breast. Their pathology, symptoms, diagnosis and treatment. London: Edward Arnoled \& CO; 1931:483-4.

3. Diaz NM, Palmer JO, McDivitt RW: Carcinoma arising within fibroadenomas of the breast; a clinicopathologic study of 105 patients. AM J Clin Pathol 1991, 95:614-22.

4. Buzanowski-Konakry K, Harrison EG Jr, Payne WS: Lobular carcinoma arising in fibroadenoma of the breast. Cancer 1975, 35:450-6.

5. Ozello L, Gump FE: The management of patients with carcinomas in fibroadenomatus tumours of breast.Surg Gynecol Obstet 1985, 160:99-104.

6. Dupont WD, Page DL, Parl FF, Vnencak-Jones CL, Plummer WD Jr, Rados MS, Schuyler PA: Long term risk of breast cancer in women with fibroadenoma. N Engl J Med 1994, 331:10-15.

7. Pick PV, Lossifides IA: Occurrence of breast carcinoma within a fibroadenoma. Arch Pathol Lab Med 1984, 108:590-4.

8. Dechens L, Jacob S, Fabia J, Christen A: Beware of breast fibroadenomas in middle aged women. Can J Surg 1985, 28:372-4.

9. Iyengar KR, Peh SC, Yip CH, Vijayananthan A: Infiltrating Duct Carcinoma within a fibroadenoma. Indian Journal of Cancer 2009, 46:244-46.

10. Abe H, Hanasawa K, Naitoh H, Endo Y, Tani T, Kushima R: Invasive ductal carcinoma within a fibroadenoma of the breast. Int J Clin Oncol 2004, 9(4):334-8.

11. Stafyla V, Kotsifopoulos N, Grigoriades K, Kassaras G, Sakorafas GH: Lobular carcinoma in situ of the breast within a fibroadenoma. A case report. Gynecol Oncol 2004, 94(2): 572-4.

12. Kurosumi M, Itokazy R, Mamiya Y, Kishi K, Takayama Sh, Nagasawa M, Kurihara T, Suemasu K, Higashi Y: Invasive ductal carcinoma with a predominant intraductal component arising in a fibroadenoma of the breast. Pathol Int 1994, 44(12):874-7.

13. Kujiper A, Preisler-Adams SS, Rahusen FD, Gille JJP, Wall E, van Diest PJ: Multiple fibroadenomas harboring carcinoma in situ in a woman with a family history of breast/ ovarian cancer. J Clin Pathol 2002, 55:795-7. 
14. Kujiper A, Mommers EC, Van der Wall, Van Diest PJ: Histopathology of the fibroadenomas of the breast. Am J Clin Pathol 2001, 115:736-42.

15. Carter CL, Corle DK, Micozzi MS, Schatzkin A, Taylor PR. A prospective study of the development of breast cancer in 16,692 women with benign breast disease. Am J Epidemiol $1988 ; 128: 467-77$.

16. Borecky N, Rickard M. Preoperative diagnosis of carcinoma within fibroadenoma on screening mammograms. J Med Imaging Radiat Oncol 2008;52:64-7.
17. Sklair-Levy M, Sella T, Alweiss T, Craciun I, Libson E, Mally B. Incidence and Management of Complex Fibroadenomas. Am J Roentgenol 2008; 190:214-8.

18. Baker KS, Maonsees BS, Diaz NM, Destouet JM, McDivitt RW: Carcinoma within fibroadenomas: mammographic features.Radiology 1990, 176(2):371-374.

19. Fondo EY, Rosen PP, Fracchia AA, Urban JA: The problem of carcinoma developing in a fibroadenoma: recent experience at Memorial Hospital. Cancer 1979, 43(2): 563-567. 